\title{
Management Information Systems and Its Support to Sustainable Small and Medium Enterprises
}

\author{
Srinivas Nowduri ${ }^{1} \&$ Shafi Al-Dossary DBA ${ }^{2}$ \\ ${ }^{1}$ College of Business, Bloomsburg University of Pennsylvania, Bloomsburg, USA \\ ${ }^{2}$ Faculty of Business Studies, Arab Open University, Fahaheel, Kuwait \\ Correspondence: Srinivas Nowduri, College of Business, Bloomsburg University of Pennsylvania, 400 E $2^{\text {nd }}$ \\ Street, Bloomsburg PA 17815, USA. E-mail: snowduri@bloomu.edu
}

$\begin{array}{lc}\text { Received: August 22, } 2012 & \text { Accepted: September 3, } 2012 \quad \text { Online Published: October 1, } 2012 \\ \text { doi:10.5539/ijbm.v7n19p125 } & \text { URL: http://dx.doi.org/10.5539/ijbm.v7n19p125 }\end{array}$

\begin{abstract}
Management information systems (MIS) and its support to "sustainability"are outlined with a special emphasis to small and medium enterprises (SMEs) development. An overview and strategy of a sustainable MIS(SMIS) is described as a measuring, managing and innovative tool for todays' sustainable SMEs (SSMEs). SSMEs and their advantage over other SMEs and multinational companies (MNCs) in the light of sustainability factors are detailed. Some existing challenges along with few limitations of SMIS are presented, along with fourrecommendations for better effectiveness of SMIS.
\end{abstract}

Keywords: sustainability, management information systems, small and medium enterprises, decision making, information systems

\section{Introduction}

Every business organization in this era needs an information system (IS) to keep track of all business activities, right from business planning, till the product delivery via manufacturing and quality cycles. In view of huge order-turnover process, keeping track of the number of resources, various business activities, and monitoring the overall business process, is becoming a real challenge to many establishments. Most of the IS used in these processes are data centered, run on enterprise software, pertaining to a specific business. These IS are try to offer high quality of service, dealing with large volumes of data and business process supportive. With their innate capability of storing, retrieving and using specific domain related information, such as medical, nursing or management, IS have gained movement in all business markets. In most of the countries around the world, with rapidly growing economic concerns, a fresh graduate is forced to think like an entrepreneur, to be successful in life.

An entrepreneur (being owner cum manager of small and medium enterprise (SME)) is any person who quickly recognizes an opportunity, within his/her vicinity and tries to start a business to fulfills consumer needs, which other people might have not recognized (Steve M \& Caroline G, 2012). The author quickly goes over the following questions such as what will be produced, when and how it will be produced, and finally who will produce it?

As a quick and smart decision-maker, an entrepreneur should be equally capable toinherently intertwining with proper management and organizational business process. This decision making activity need not be confined to just his/her specific organization but also for individuals who greatly rely on these decisions for their survival in the highly competitive arena of entrepreneurship (Al-Zhrani, 2010). There by an entrepreneur in this modern era, should be very clear at many aspects of the business, with proper planning to start up, coupled with quick (time constrain) and smart (quality constrain) decision-making (DM) activity at each stage. Since several decades, Management information system (MIS) has been an increasingly used software tool for making institutionalization/business related decisions. Decision support systems (DSS), emerged as a separate sub-field under MIS for intelligent DM activities.However, despite the immense benefits that result from using MIS in decision making, some critics have, reportedly, been slowly_but surely-asserting that MIS poses surmountable detrimental effects to organizations and should thus be used sparingly or avoided if possible (Demetrius, 1996). In this modern era, deterioration of the natural environment poses risks and opportunities for business organizations. This has fine tune the thought process of a modern entrepreneurs towards 'sustainability 
factors' and 'innovative environmental strategies'. This results in the authors' new definition of sustainable SMEs (SSMEs), where the entrepreneur is expected to focus more fine-tuned towards social responsibility and sustainable development, rather than purely on several business activities. The research on these SSMEs is still in its preliminary stages, where the new business owners need to be educated from two perspectives viz., (a) environmental responsibility such as steps in reduce, recycle and reuse raw materials and waste materials and (b) technology up gradation such as use of computer based systems such as MISs, as a measure, management and innovative tools for strategic business advantages, where the current research is primarily focuses.

Technology up gradation has been a challenging task for many SMEs in this era, due to increasing competitive markets, dependency on supply chain and improving the customer base. For this reasons, MIS is often referred to as business process management (BPM), as innovation of the technology finds its roots in automating the processes that involve human. This makes MIS more elegant in its capability to automate several business related processes such as process modeling, process monitoring, application programs, application integration and finally rapid application development tools. This came as a helping hand to an entrepreneur to implement several business strategies/policies and to make some crucial business decisions.

This research is mainly focus on the MIS impact on SSMEs and aimed at guiding modern entrepreneurs (Srinivas N, 2012). SSMEs are basically looking at improving the environmental impact on small businesses and green business practices. Initial focus of this research is on sustainability and its link to todays' SMEs. Later on it focuses on MIS development and its support towards sustainability development. Finally concludes with some advantages of SMEs over multinational corporations (MNCs) with reference to sustainability factors along with some recommendations to a modern entrepreneur.

\section{Sustainability and Small and Medium Enterprises}

This background literature review section is focus on the fine linkage between sustainability and SMEs. Thereby it concentrates on the aspects of sustainability factors and their influence on the SMEs development.

Any prospective entrepreneur normally focuses on identifying new opportunities for creating value for customers or users and commercially developing those opportunities to establish a profitable business. In most of the developing countries, SMEs are marked as an important source of employment, particularly for low-skilled workers, as well as women and young people, who usually make up the greatest proportion of the unemployed in emerging economies (VittalA \& Shivraj K, 2008). This also makes entrepreneur more challenging in view of budget constraints to face his/her individuality and his/her hope for success. For most of the SMEs speed can agility are two key main weapons.

These days starting small businessesis really found to be more and more challenging, especially with the industrial revolution teaching us a great moral: people's actions could damage the environments. This seminal knowledge has quickly strengthened people with the observable destruction of natural areas such as earth quakes; tsunami, rain/river water floods, etc. lead to the growth of conservation movement, especially in the industrial (corporate) world. Thus the 'sustainability' has become an important issue for every nation on this planet, as it is linking the various vital issues such as poverty-environment, economy-environment (known as ecological economics), industry-environment (known as industrial ecology) etc. For example, the ecological economics is well connected with the issues of from both economics and ecology (ecological attributes), with a primary concern of transformation to a green economy in the context of sustainable development (Basu A, etal, 2008).

Therefore sustainability is relatively a new concept concerning more about better living and environmental improvements. With this new vision, the focus of the entrepreneur is solely focus on the certain non-economic motives aimed at searching for opportunities for new products or services or new technologies or production processes that alleviate social or environmental conditions, make more efficient use of energy and natural resources, and harness new resources that are more abundant, cheaper to produce, and less harmful to society (Basu, etal 2008). Therefore in recent decades this sustainability development becomes a major issue in most of the advanced nations around the world. As a result, sustainable development is greatly supported by several governments, the World Bank couples with some regional and industrial development banks.

An entrepreneurs' psychology and work environment is much easy access bed for implementing sustainability factors, as SMEs are more responsive to service and support requests and more willing to offer on-site service. The assimilative capacity of the environment, such as absorb wastes and pollution without permanent or irreversible damage. This type of work process, inevitable requires a work break down (WBD) structure, where the need of SMEs is inevitable, as they particularly located close to the customer. SMEs are also effective in manipulating the technologies, where new technologies may increase carrying capacity or decrease the impact of particular activities. In such crucial situations, manipulation of financial resources and organizational skills 
play a pivotal role with the immense support from SMEs.

In the similar veinan industrial ecology, deals with interconnectivity of production systems, with a central idea of minimizing the industrial waste. This mainly composed of many human, financial, legal and technological constraints, where SMEs comes in handy. This is mainly so because SMEs are capable of utilizing stand-alone solutions in their work process. On the other hand SMEs will never get enough monetary support and some to spark like large businesses. This demands an extra precaution to entrepreneurs towards better money management. Most of the small and medium enterprises (SMEs) are quite often prone to poor cash flow management for various obvious reasons such as maturity of the entrepreneur, lack of financial training, lack of awareness, lack of detailed feasibility study, lack of leadership qualities etc. In general poor flow of cash can spell doom to an otherwise healthy organization - applicable to both SMEs as well as multinational companies (MNCs).

\section{MIS and Its Support to Sustainability Development}

This section of literature review surfaces certain information systems supports for sustainability development. A broad overview of MIS and primary support for management decision making at various levels of management is detailed. Later part is focus on linking the MIS and its support to green business development.

MIS is a computer based information system that provides for management oriented reporting based on transaction processing and business operations of the organization. This MIS provide reports to various managers among the middle and low level managers of the organization. Especially, for middle level managers MIS provides the organizational performance reports, which in turn help predicting the future performance of the organization. MIS helps all levels of people within a business organization. The upper level management in an organization uses MIS for strategic decision, like executive information system (EIS). The middle level management person uses MIS for their tactical decisions, like supervisory information systems (SIS). The low level management (line workers) uses MIS for their day-to-day activities, like transaction processing systems (TPS). Thereby MIS help managers exercise effective controlling of organizational resources and business activities is a computer based system designed to get right information at the right time, in any business organization.

Nowadays, every business market leading enterprise will have at least one core competency - that is, a function they perform better than their competition. By building an exceptional MIS into their enterprise it is possible to push out ahead of the competition. MIS systems provide the tools necessary to gain a better understanding of the market as well as a better understanding of the enterprise itself.SMEs need to withstand to the changes in global, social and environmental circumstances. For this SMEs need to incorporate sustainability factors in their organizational business plan. This is very much possible, especially in view of SMEs size and limited resources. At the same time, this makes SMEs more resilience to the capability for survival, adapt and grow in the face of turbulence changes in the market place. Finally this makes SMEs more innovative and productive in terms of reduction of raw materials and energy usage (Fiksel J, 2006).

An entrepreneur, being owner cum manager, needs to manage the entire business process as well as resource needs. There comes MIS handy for estimating as well as resource calculations. For example, the information from MIS helps an entrepreneur in several ways as:

- $\quad$ To predict the number of sales people needed

- Technology needs

- Feasibility of the SME's strategic location

- Summary of sales reports

Past literature on MISis clearly indicates MIS as a computer based system composed of three main facts, from three different perspectives as (Kumar P.K., 2006):

1. Management

2. Information

3. Systems

Each of these facts contributes to sustainability in many ways. Some business establishments has already start implementing environmental management systems (EMS), management programs requiring information systems to monitor, evaluate, improve and communicate environmental performance, that includes information baselines on 'in-put' such as energy, water, material, etc., that results 'out-put' such as waste, emission, etc. 
(Melville N. P, 2010). Before we go through these details let us have a look at these different perspectives of MIS on sustainability.

Management and Sustainability: This primarily addresses how management in this modern era addresses the sustainability factors? Management in any business organization needs to address from three different perspectives, first environment, where the management techniques need to apply to protect critical environmental factors such as air, water, climate and ecosystems. Second fine tune the management,in improving the needs of the present and future generation. Finally address the management techniques towards long-term economic performance.

Managing the sustainability issues always is connected with three main factors: (a) economic and commercial imperatives such as products, (b) factors related to environment such as protecting earth's biosphere (c) societal needs such as community demands. Most of the small business owners does not see these issues in the introductory stages of their business, but eventually realize as the business progress.

Information and Sustainability: This part is mainly addresses the linkage between the information and sustainability. Making information technology (IT) infrastructure (within the business organization) in such a way that it increases the efficiency of the IT infrastructure and to reduce greenhouse gas emissions caused by computing and IT-related activities. For example, establishing a central desktop power management software for saving power, also by putting computers in sleep mode. For majority of the business owners till yesterday 'information' needs are limited to their business concern, but slowly the environmental laws and environmental management systems are enforcing the 'sustainability' concept for small business owners. Environmental literacy is creating a positive attitude change to the modern entrepreneurs. For example, pro-active pollution prevention measures are one of the seminal aspects for small business owners.

Computer Systems and Sustainability: Many business organizations start implementing environmental management systems (EMS), requiring information to monitor, evaluate, improve and communicate environmental performance, with inputs such as air, water and materials and outputs as waste, emissions. This has given enough vision in to the future with renewable energy sources to reduce the energy costs. There are some studies of environmental sustainability incorporate the information systems perspectives (Sidorova A, etal, 2008) (Carberry, 2001). These systems research significantly contribute to knowledge at information, organization and the natural environment. Thus created environmental strategies take care of certain environmental responsibility and ultimately improve the natural environment (Carberry, 2001).

For a successful entrepreneur in this era, as shown below in Figure 01, there are three challenges important for designing and improving his/her SME while incorporating the sustainability factors.

1) Apart from improving economic factor he/she needs better understanding about environmental and social impact of business.

2) Applying the business impacting sustainability factors for creating a better competitive market trend.

3) Interlinking the sustainability strategy with the existing corporate business strategy.

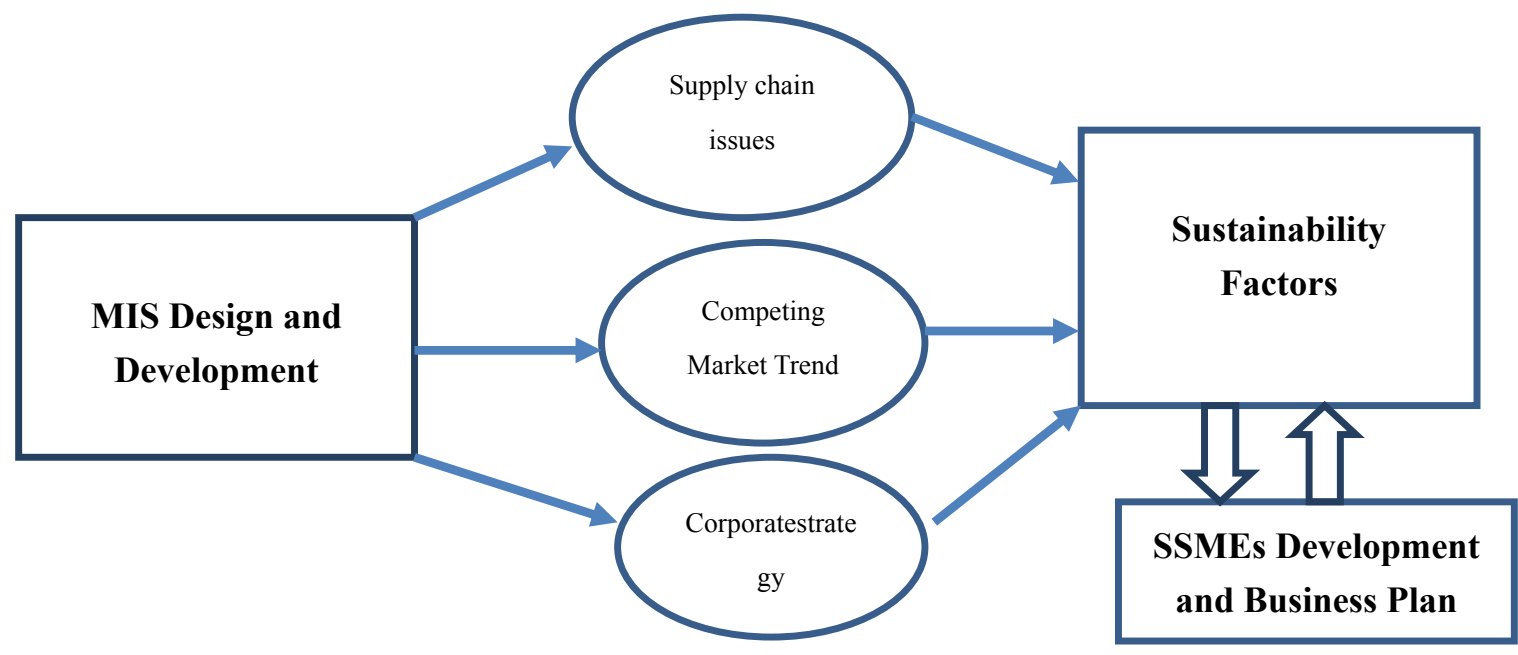

Figure 1. Entrepreneur business process in modern era 
It is very clear that, MIS design and implementation is revamped through another school of thought to fit into SMIS. At the same time SMEs being marching towards SSMEs for better environmental protection and support. Most prominently as a supporting force and guidingsoftware tool for next generation entrepreneurs.

\section{Sustainability MIS as a Measure, Manage and Innovation Tool for SSMEs}

Once the business world confronted with the combined challenges of climate change and sustainable development, MIS is quickly upgraded to measure, environmental management innovation tool; which authors defines to be sustainability MIS (SMIS). With reference to SMEs these facets can be further exemplified and detailed with the help of sustainable computing concepts, solely focus on the direct and indirect impact of information technology on our environment.

In the case of SMIS, the entrepreneur needs to be given his/her business specific information, to start up and continuation of business. At this stage one needs to incorporate the sustainability factors that belong to green management. Overall, the SMIS encompasses the both management techniques and environmental factors, to help entrepreneur in planning, organizing, initiate and control business operations within the businesses jurisdiction.

At the same time, SSME being the brain child of an entrepreneur, where the management needs to be originate from single brain, at least during the initial stages of its inception. There by a management can only exist when there are subjects/workers to be managed (Al-Zhrani, 2010) (David A \& Graham P, 2005).

There are a number of factors that promote and support sustainability development, such as freedom, equality, solidarity, tolerance, respect for nature and taking on the responsibility of managing economic and social development globally (Shepherd D, et al. 2009) (Tolentino A, 2012). In view of SME's low budgets and less manpower, it is clear that sustainability is not that cake walk for its full implementation, however the following are some of the factors (with reference to SSMEs), not limited to, that an entrepreneur should keep in mind:

a) Possible business risks: Ensuring the business can ensure the workers' health and safety in a long term, in smart building environment.

b) Process and productivity issues: Ensuring that the SMEs are using (as much as possible) the natural energy or resources, and renewable energy.

c) Sustainable workforce: The workforce who are comfortable in using/creating/maintaining the energy efficient electric grids and processes, videoconferencing set ups for discussions/meetings and recyclable product usage.

\section{Advantages of SMEs over MNCs with Reference to Sustainability Factors}

Most of the multinational companies (MNCs) are at once started as an SME. In this modern era, MNCs start developing sustainable value chains by effectively incorporating the key capabilities of their MSE partners. This way each MNC start working with some SMEs for better productivity and quality improvement with driving innovations. In addition SMEs also influence MNCs by taping local talents and local markets. This way each MNC is slowly start influenced by local SMEs in adapting sustainability factors within a given region or community. This basically improves the long-term collaborative partnership with SMEs as their suppliers. The following are some advantages of considering SMEs as suppliers by MNCs:

1) Influencing the untapped markets if any...

2) Giving an opportunity to minority-entrepreneurs

3) Increase competitive market position and ensuring long-term success

SMEs are definitely in a better position when compared to MNCs, in view of their customers personalized services, as they have enough time and opportunity to make an extra effort to realize the customer problems. Due to large volumes and nature of business, somehow MNCs cannot achieve this task. Being small SMEs have lot more flexibility to respond to customer and quickly react to market changes. Most importantly SMEs can more innovative then MNCs in view of their open and flexible experimentation, coupled with their intimate knowledge of their specific customers.

Most of the MNCs are well established since several decades, with their solid technology base for their business process automation. The need for their improvement lies in the domains like, technology upgrades, security issue and maintenance. As a supply chain to MNCs, in general SSME's business systems normally consist of smaller systems, called subsystems, which function towards ensuring efficacy of the large systems. Also, as a matter of fact, systems vary from one organization to another depending on the nature of organizational 
operations, size of the businesses and organizational priorities among many other salient factors.

Based on the foregoing definitions, MIS normally refers to a system that uses information in order to ensure apt management of businesses. Fundamentally, all the facets of MIS run concomitantly in order to ensure overall efficiency of the whole system. Failure in one part means overall failure for the other parts since they are all designed to function interdependently (Davenport \& Short, 1990). Initially MIS is aimed at making information in transaction processing systems available to management for decision-making purposes. As a result, a good MIS leads to good decision-making in business just in the same way poor management leads to proper business decision making, across various stages in the business process, results in better productivity and quality.

\section{Conclusion and Useful Recommendations}

Despite several positives facts associated with the role of SMIS and its influence on the SSME owners, the following are some challenges worth pursuing, in the light of sustainability factors.

- The dynamic nature of SMIS, especially towards development of innovative environmental strategies,might makes it difficult for some organizations to keep up with the principles, strategies, propositions or even ideas.

- Situations within organization with reference to environmental responsibility, call for different decisions to be made, across all levels of employees. This poses challenges to the design of newSMIS theorists since some MIS tend to not be adaptable.

- The institutionalization, programming, monitoring and evaluating MIS requires a lot of expertise- something which numerous organizations lack.

- The running of SMIS programs sometimes tends to be relatively costly for some SSMEs - especially small ones who are not well-endowed financially.

Based on these limitations coupled with other underlying issues that arise from the main discussion, the following recommendations are suggested:

- There should be an increased monitoring of SMIS so as to avoid falling victims of unobserved MIS which has dire ramifications, especially in view of environmental sustainability which focus on informing beliefs and associated enabling actions.

- SMIS is still long way to go for incorporating all of the sustainability factors and its associated salient issues. This caution the SSMEs owners to point to their specific business environment, else they may miss the main stream of their business.

- In view of several advantages of SSMEs over MNCs with reference to sustainability, capable of bypass certain restrictive regulations, to emerge as a competitive economic forces.

- The entrepreneur should encourage the effectuation of a mutually interdependent and balanced SMIS where his/her employees and automated systems are handled with due respect.

- Business entities should find a way inculcating teachings about new SMIS outlines and design, in order to reduce organizational waste, emissions, etc., which directly impact our society and living conditions.

- A well-defined business decision making SMIS systems should be fledged in businesses so as to provide a viable working environment in creating protection not only to their life but also to the environmental protection.

Principally, it is inherent to note that in spite of the fact that this paper is expressively analytical, more research needs to be done in order to bring more information into public know-how. Moreover, SME business owners must learn to cope up sustainability factors, with the ever changing trends in MIS usage and decision making activities. Finally, it is vital to remember that improvement in SSMEs decision making is not purely ensure customer satisfaction, but to continue the business with sustainability factors and safe continuation of business by next generation. All SMIS strategies should therefore be tailored in a way that the above business goals are achieved.

\section{References}

Allen, B., Heurtebise, A., \& Turnbull, J. (2010). Improving Information Access. Business Management US. Retrieved from http://www.busmanagement.com/article/Improving-information-access

Al-Zhrani, S. (2010). Management information systems role in decision-making during crises: case study. Journal of Computer Science, 6(11), 1247-1251. 
Basu A, Osland A., \& Solt, M. (2008). A New Course on Sustainability Entrepreneurship Retrieved from http://nciia.org/conf08/assets/pub/basu1.pdf

Carberry J (2001). Using Environmental Knowledge Systems at DuPoint, Information Systems and Environment, D.J Richards, B. R. Allenby, \& D. Compton (eds.), Washington, DC: National Academy of Engineering. 81-86.

Chambers, R. J. (1964). The role of information systems in decision making. Management Technology, 4(1), $15-25$.

Cohen B., \& Winn M. (2007). Market imperfections, opportunity, and sustainable entrepreneurship, Journal of Business Venturing, 1(22), 29-49.

Davenport, T. H., \& Short, J. E. (1990). The new industrial engineering: Information technology and business process redesign. MIT Sloan Management Review. Retrieved from http://sloanreview.mit.edu/the-magazine/articles/1990/summer/3141/the-new-industrial-engineering-inform ation-technology-and-business-process-redesign/2/

David A., \& Graham, P. (2005). A Critical Analysis of Decision Support Systems Research, Journal of Information Technology, 20, 67-87.

Demetrius, K. (1996). The role of expert systems in improving the management of processes in total quality management organizations. SAM Advanced management Journal. Retrieved from $\mathrm{http}: / / \mathrm{www}$. allbusiness.com/management/591381-1.html

Fiksel, J. (2006). Sustainability and Resilience: towards a system approach, sustainability: Science, Practice. \& Policy, 2. 14-21.

Jahangir, K. (2005). Improving organizational best practice with information systems. Knowledge Management Review. Retrieved from http://findarticles.com/p/articles/mi_qa5362/is_200501/ai_n21371132/

Jarboe, K. P. (2005). Reporting intangibles: A hard look at improving business information in the U.S. Athena Alliance. Retrieved from http://www.athenaalliance.org/apapers/ReportingIntangibles.html

Kumar, P. K. (2006). Information System-Decision Making. IndianMBA. Retrieved from http://www.indianmba.com/Faculty_Column/FC307/fc307.html

Jawadekar. (2006). Management information systems: Texts and cases. New York, NY: McGraw

Hill. Kirk, J. (1999). Information in Organizations: Directions for Information Management. Information Research, 4(3).

Lingham, L. (2006). Managing a business/ Management information system. All Experts. Retrieved from $\mathrm{http} / / /$ en.allexperts.com/q/Managing-Business-1088/management-information-system.html

Melville, N. P, (2010). Information Systems Innovationfor Environmental Sustainability. MIS Quarterly, 34(1), $1-21$.

March Rhodes, J. (2010). The Role of Management Information Systems in Decision Making. Retrieved from http://www.ehow.com/facts_7147006_role-information-systems-decision-making.html

Sidorova A, Evangelopoulos, Valacich J., \& Ramakrishnan, T. (2008), Uncovering the Intellectual Core of the Information Systems Discipline, MIS Quarterly, 33(3), 467-482.

Shepherd, D.A., Kuskova. V., \& Patzelt H. (2009), Measuring the values that underline Sustainable Development: The Development of Valid Scale. Journal of Economic Psychology, 30, 246-256.

Srinivas N (2012). Management information systems and its support to small and medium enterprises owners, Proceeding of the society for advancement of management. International Business conference, Las Vegas, March30-April 01.

Steve M., \& Caroline, G. Entrepreneurship: Starting and Operating a Small Business ( ${ }^{\text {rd }}$ Edition). Pearson Publication, New York, USA.

Tolentino, A. (2012). NGOs and Business for Sustainable Development, Environmental Policy and Law, 42(1).

The Maniac. (n.d.). Management information system: The center of management decision making. Helium. Retrieved from http://www.helium.com/items/242575-management-information-system-the-center-of-management-decisio n-making

UStudy.in. (2010). MIS and decision making. Retrieved from http://www.ustudy.in/node/1009

Vittal, A., \& Shivraj, K. (2008). Role of IT and KM in improving project management performance. VINE, $38(3), 357-369$. 